\title{
Thermal Stir Welds in Titanium
}

\author{
RICHARD W. FONDA, KEITH E. KNIPLING, and ADAM L. PILCHAK
}

\begin{abstract}
Although conventional friction stir welding (FSW) has proven unsuccessful in joining thick sections of alpha and near-alpha titanium alloys, thermal stir welding, a variant of the FSW process in which an external heat source is used to preheat the workpiece, is demonstrated to be able to reliably join $12.3-\mathrm{mm}$-thick plates of $\mathrm{CP}$ titanium. This paper describes the microstructures and textures that develop in these thermal stir welds. The observed microstructure was used to reconstruct the high-temperature microstructure and texture present during the welding process and therefore reveal the genesis of the welding structures.
\end{abstract}

DOI: $10.1007 / \mathrm{s} 11661-015-3218-4$

(C) U.S. Government Work. Not Protected by U.S. Copyright 2015

\section{INTRODUCTION}

FRICTION stir welding (FSW) is a solid-state joining process that was originally developed to join aluminum alloys, although it has since been adapted for many other alloys including steels and titanium. ${ }^{[]}$In the FSW process, a rotating, non-consumable tool is plunged into the material to be joined, where it generates heat in the surrounding material through frictional and plastic deformation heating. The heat reduces the flow stress in the surrounding material, allowing the rotating tool to deform or 'stir' that material. The resultant material flow transfers material around the tool to be deposited in its wake as a consolidated weld. ${ }^{[1,2]}$

There have been many proposed shapes of FSW tools, but conventional tools often consist of a cylindrical or truncated conical pin and a shoulder. The pin produces heat within the workpiece and generates the rotational (usually with a vertical component) flow around the tool. ${ }^{[3]}$ The shoulder introduces additional heat into the top surface and subsurface regions of the workpiece while constraining the deformed material. The tool shoulder produces a majority of the heating in thin sheet welds, while the pin produces a majority of the heating in thick workpieces. ${ }^{[4]}$

While there have been many studies on FSW in titanium alloys, few of those ${ }^{[5-15]}$ have focused on alpha or near-alpha titanium alloys. Most of those studies have focused on thin section (from 2- to 6.35-mm-thick sheet) welding, where the heat generated by the shoulder can more readily be transferred to the base of the weld during welding. While FSW of thicker $(12.7 \mathrm{~mm})$ plate has been performed on alpha ${ }^{[7]}$ and near-alpha ${ }^{[6,10,15]}$ titanium alloys, no stable welding conditions (tool design, tool rotation, weld speed, and welding forces)

RICHARD W. FONDA, Section Head, and KEITH E. KNIPLING, Metallurgist, are with the Materials Science \& Technology Division, Naval Research Laboratory, Washington, DC. Contact email: Richard.Fonda@nrl.navy.mil ADAM L. PILCHAK, Materials Research Engineer, is with the Air Force Research Laboratory, Materials and Manufacturing Directorate, Wright Patterson AFB, $\mathrm{OH}$.

Manuscript submitted March 26, 2015.

Article published online November 3, 2015 have been found to consistently achieve defect-free welds in such thicker sections of these alloys.

The difficulty in FSW alpha and near-alpha titanium alloys arises from a combination of tool limitations, low thermal conductivity, and the temperature dependence of flow stress. The high strength and elevated temperatures required to friction stir weld titanium, in combination with the chemical reactivity of the titanium workpiece, limit possible tool materials that can be used to friction stir weld these alloys. The tool materials used, typically a strengthened tungsten alloy, cannot retain many of the complex geometries used to friction stir weld more conventional materials such as aluminum. Thus, most tool designs for welding titanium are relatively simple and do not generate the vertical material flow typically observed in aluminum friction stir welds. In addition, titanium's moderate thermal conductivity and high heat capacity further inhibit heat transfer away from the tool. Thus, heat generation from the shoulder is ineffective for heating the base of the weld, establishing a thermal gradient through the thickness of the weld that only worsens for thicker sections. Furthermore, the large temperature dependence of the flow stress ${ }^{[16]}$ will cause this thermal gradient to generate an unacceptably high gradient in flow stress through the thickness of the material that will prevent suitable welding conditions from being maintained through the depth of thicker welds.

The moderate thermal conductivity and the temperature dependence of the flow stress also constrain FSW of alpha and near-alpha titanium to immediately above the beta transus temperature. Lower welding temperatures require significantly higher machine forces and inhibit efficient consolidation of material behind the tool due to the higher flow stress of the low-temperature alpha phase. Higher welding temperatures cannot efficiently transmit the rotational plastic deformation through the lower flow strength beta phase surrounding the tool. In addition, temperatures significantly exceeding the beta transus temperature can also facilitate undesirable levels of grain growth. The resulting narrow temperature range for acceptable FSW needs to be achieved and maintained in all regions of the friction stir 
weld. This limitation has so far prevented conventional FSW from being able to consistently produce high-quality, industrially robust, solid-state joints in thick-section welds of alpha and near-alpha titanium. ${ }^{[6,7]}$

In order to accomplish FSW of thick-section titanium, it is necessary to improve the material flow ('stirring') and/or generate heat more uniformly through the thickness of the material. While advances in tool materials and designs may yet improve the material flow during welding, and passing an electrical current through the tool ${ }^{[17,18]}$ may enable an improved distribution of heat generation, the thermal stir welding (TSW) process ${ }^{[19-21]}$ currently holds the most promise for welding thicker sections of alpha and near-alpha titanium. TSW uses an external heat source to preheat the workpiece ahead of the rotating tool (see Figure 1), separating much of the heating and stirring processes inherent in the FSW process. This TSW process has demonstrated the capability to weld CP Ti with no loss in strength - the weld-affected regions meet or exceed the parent metal strength. ${ }^{[22]}$ While laser-assisted FSW has also been demonstrated as a viable technique for the welding of high-strength materials, ${ }^{[23]}$ the heat source used in this study was an induction coil due to its ability to inject heat into a larger region of the workpiece.

\section{EXPERIMENTAL}

The welds examined in this study were fabricated on the solid-state joining equipment at the NASA-Marshall Space Flight Center by Keystone Synergistic Enterprises using an induction coil to preheat the workpiece to ahead of the tool. The weld joined two 30-cm (12 inch)-long plates of $12.3-\mathrm{mm} \quad(0.5$ inch $)$-thick

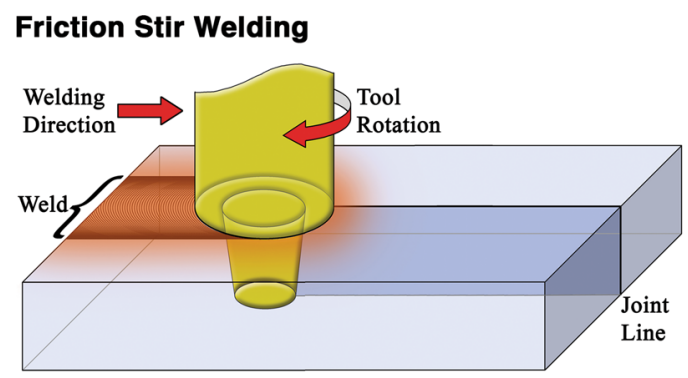

Thermal Stir Welding

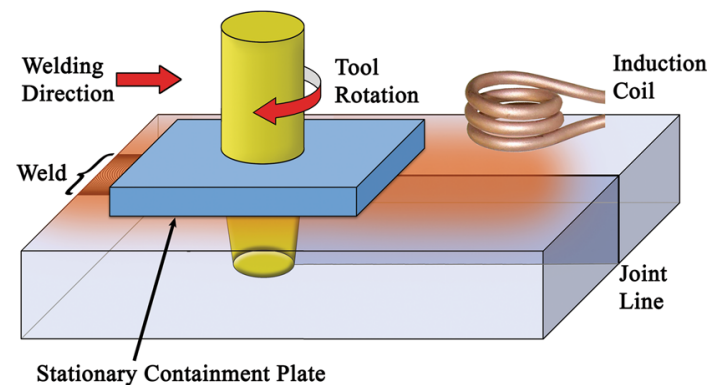

Fig. 1-Schematic of the conventional friction stir welding and thermal stir welding processes. commercial purity Grade 2 titanium in a butt weld configuration at a $300 \mathrm{rpm}$ tool rotation and $7.6 \mathrm{~cm} / \mathrm{min}$ (3 inch/min) welding speed under argon shielding. The TSW process used was similar to earlier reports of the TSW technique, ${ }^{[19-21]}$ except that a water-cooled stationary containment sleeve was used to constrain material during welding and generate a smooth surface finish.

The weld was preheated with an induction coil (schematically shown in Figure 1(b)) designed to generate heat through the thickness of the weld. The welding was conducted in an inert gas chamber to minimize oxidation during the welding process. This weld was sectioned in both transverse cross section and in plan-view cross section at the plate mid-thickness. These sections were prepared metallographically up to a final polish with $0.05 \mu \mathrm{m}$ silica for analysis by electron backscatter diffraction (EBSD). A JEOL JSM-7001F SEM operating at $20 \mathrm{kV}$ and equipped with a TSL/ EDAX Hikari EBSD detector was used to acquire the EBSD data with a step size of $1.0 \mu \mathrm{m}$. Analysis of the EBSD data was performed with the TSL/EDAX OIM Analysis 5.31 software package.

The alpha phase EBSD data was further post processed to reconstruct the high-temperature beta phase microstructure that would have been present during welding. To accomplish this, the as-measured data were segmented into unique alpha colonies using a tolerance angle of 2 deg. Next, the angle/axis misorientations associated with observed alpha phase clusters containing at least four different alpha colony orientations were compared to the set of six (including the identity) allowed misorientations for alpha variants inherited from the same parent beta grain. ${ }^{[24]}$ If all angle/axis pairs were allowed, the six possible parent beta grain orientations were calculated for each alpha variant within the cluster and compared to determine whether they share a common parent orientation (within the 2 deg tolerance). This process was repeated across the sample until all measured alpha data points were considered. It is important to note that the reconstruction process was only valid for the stir zone microstructure because it exceeded the beta transus and then transformed allotropically into multiple alpha variants within each prior-beta grain. The base plate microstructure consisted of alpha grains with no evidence of transformation, so reconstruction of those grains was neither possible nor relevant to the interpretation of the stir zone data.

\section{RESULTS AND DISCUSSION}

The shape of the weld nugget of this CP titanium thermal stir weld is displayed in the transverse cross section shown in Figure 2. The weld nugget has a basin shape with a sharp decrease in width towards the base of the weld, which is consistent with measured peak temperature variations. Separate thermocoupled heating trials ${ }^{[7]}$ reveal that while the induction heating produces similar temperatures through the top and middle of the welds, the temperatures generated near the bottom of 
the welds were $80 \mathrm{~K}$ to $140 \mathrm{~K}$ lower, depending on the translation rate of the plate. The peak temperatures achieved during these thermocoupled welding trials exceeding the beta transus temperature of $1186 \mathrm{~K}$ $\left(913{ }^{\circ} \mathrm{C}\right)$, ranging from $1198 \mathrm{~K}\left(925^{\circ} \mathrm{C}\right)$ to more than $1313 \mathrm{~K}\left(1040{ }^{\circ} \mathrm{C}\right)$, depending on the parameters used.

Initial analysis of the textures produced within the thermal stir weld was conducted on the plan-view cross section, and the results are shown in Figure 3. That orientation preserves a similar misorientation between the local weld texture and the surface normal across the entire weld due to the conical symmetry of the welding-induced deformation. It also exhibits the expected rotation in shear direction across the weld that arises from variations in the tool tangent orientation. ${ }^{[25-27]}$ Both EBSD images and textures were acquired across the weld and into the base plate on both sides of the weld to observe variations in microstructure and texture. The color indicates the crystallographic orientation of each grain that is aligned with the plate normal (the tool rotation axis), revealing a relatively constant orientation of red and blue grains across the weld nugget surrounded by a narrow transition region (boxed regions) and then the primarily orange base plate.

The base plate consists of a relatively uniform distribution of somewhat equiaxed alpha grains (Figure 4(a)) that exhibit a rather weak basal texture with $[0001]_{\alpha}$ aligned with the plate normal direction (see two pole figures on either side in Figure 3 and corresponding texture strength). This microstructure is typical of subsolvus rolled titanium. The grain structure, texture, and texture strength change rapidly at the weld nugget boundary into larger, more angular grains with a more complex and stronger texture. In the weld nugget,

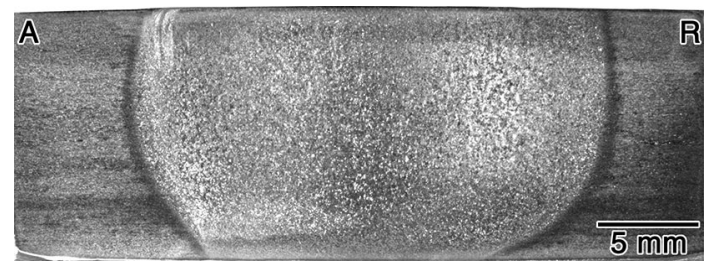

Fig. 2-Optical micrograph of the transverse cross section of the thermal stir weld examined in this study. the grain structure consists of somewhat refined grains containing packets of parallel alpha laths (see Figure 4(b)). EBSD images of this structure display both angular patches of the same alpha orientation as well as long, narrow structures that likely correspond to individual laths. A strong and relatively uniform texture is maintained across the weld nugget, varying only in orientation about the tool, as expected from the conical symmetry of the 'stirred' region surrounding the tool. Similarly, a rotation of the shear direction and the resultant texture develops across the weld nugget with the tangent of the rotating tool, ${ }^{[27]}$ as shown in Figure 3.

The microstructure observed at the weld center (see Figure 5) is typical of the microstructures present across the weld nugget. The grain structure, shown in Figure 4(b), consists of irregular but relatively equiaxed grains containing one or more packets of alpha laths. The predominant grain orientation, with more than 40 pct of the alpha grains, is a basal orientation with [0001] oriented near the plate normal direction, colored red in Figure 5(a). Significant amounts of purple (with a near- $\langle 1 \overline{1} 01\rangle$ orientation) and blue (with a near- $\langle 1 \overline{1} 00\rangle$ orientation) are also present. A particularly high concentration of the near- $\langle 1 \overline{1} 01\rangle$ (blue) orientation is observed near the advancing side of the weld nugget as shown in Figure 3.

At the weld center in this plan-view section, the observed texture (see Figure 5(a)) can be directly compared to textures reported in the literature because, at this location, the shear direction is oriented towards the right (for negative shear) and the shear plane normal is oriented approximately along the welding direction for this steep-sided weld nugget geometry. ${ }^{[27]}$ Thus, the strong texture components, located at the center of the 0001 pole figure and at six locations around the periphery of the $11 \overline{2} 0$ pole figure, are consistent with the hcp $\mathrm{P}_{1}$ ideal shear texture. ${ }^{[26]}$ However, there are a number of additional texture intensity peaks that are not consistent with any hcp shear texture components.

Since the TSW was performed above the beta transus temperature, it is more relevant to examine the high-temperature beta grain structure and texture that were generated during welding than the low-temperature alpha structure that formed from that structure during cooling. The high-temperature beta grain structure and
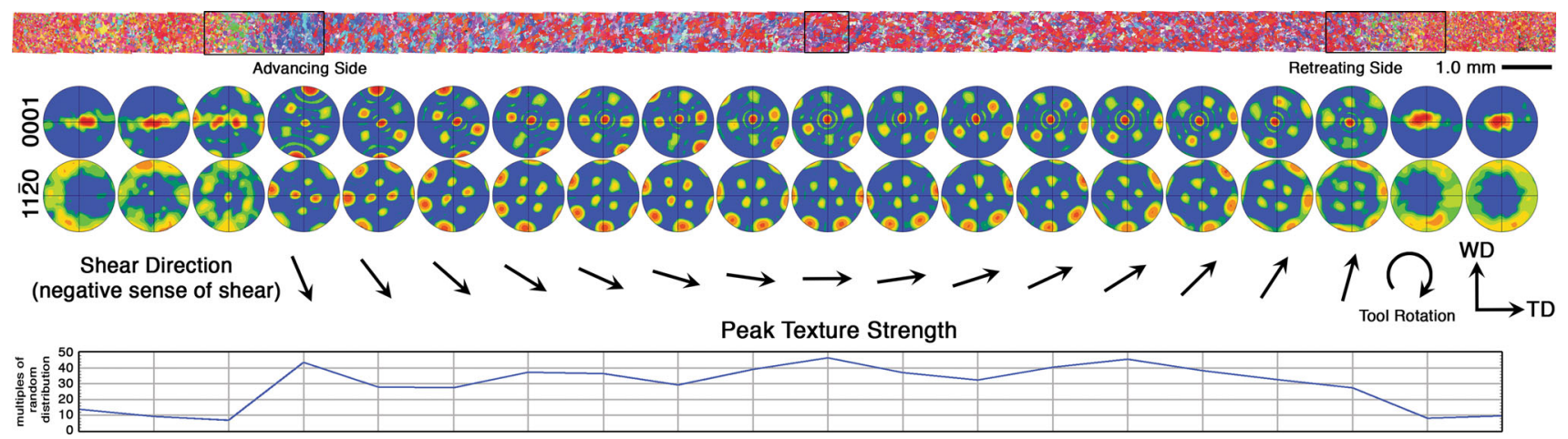

Fig. 3-Plan-view EBSD image across the weld with associated 0001 (top) and $11 \overline{2} 0$ (bottom) pole figures and shear directions. Colors indicate crystallographic orientation aligned with the plate normal direction according to the stereographic triangle shown in Fig. 5(a) (Color figure online). 

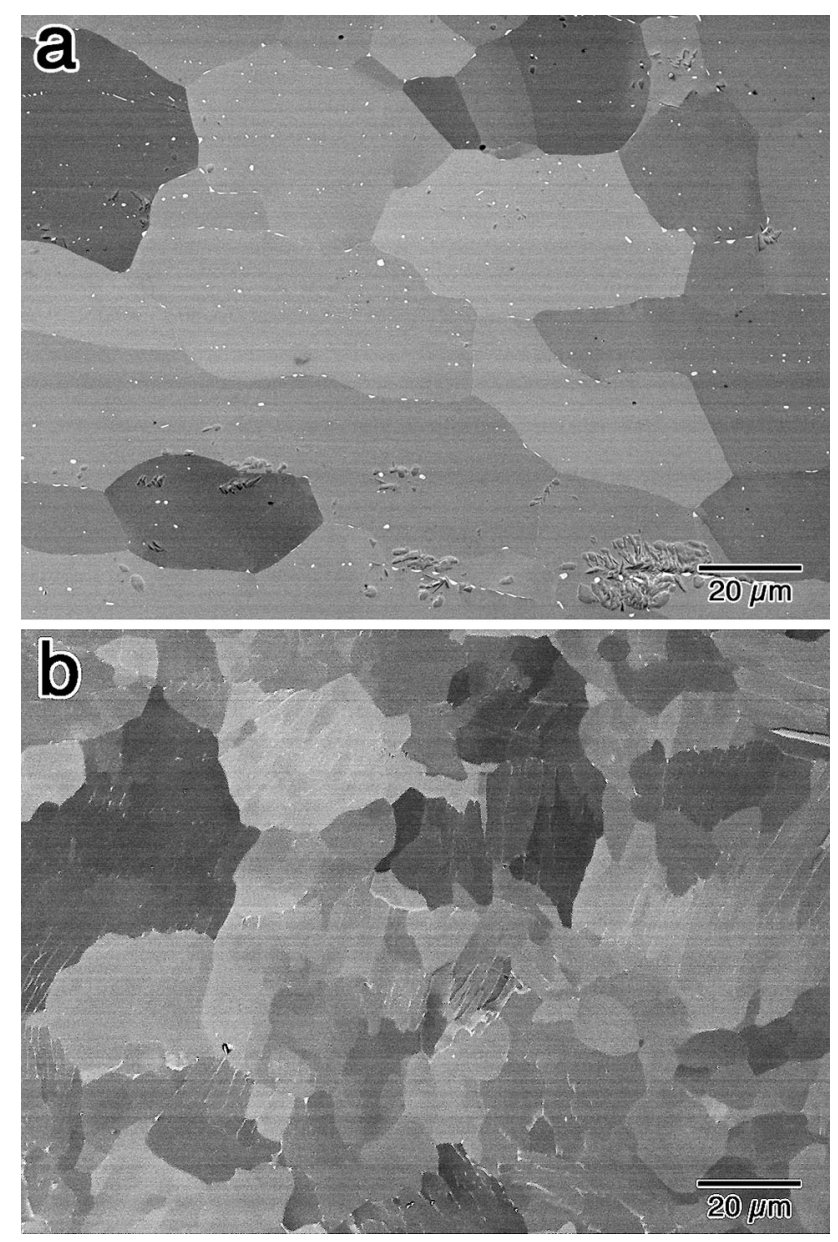

Fig. 4 -Plan-view backscatter electron images at the plate mid-thickness of $(a)$ the base plate grain structure and $(b)$ the grain structure at the center of the weld nugget.

crystallographic texture were revealed using the MRL-TiBor software package (Materials Resources LLC, Dayton, $\mathrm{OH}$ ) using a quaternion parameterization of orientation space and average alpha colony orientations to facilitate the calculations as discussed by Pilchak and Williams. ${ }^{[28]}$ This software uses a method similar to that developed by Humbert et al. ${ }^{[29,30]}$ and Glavicic et al. ${ }^{[31,32]}$ to determine the parent $\beta$ grain orientations from a group of inherited $\alpha$ variants.

The high-temperature beta grain structure that was present at the center of the weld immediately after welding was reconstructed from the measured alpha phase data (Figure 5(a)), as shown in Figure 5(b). The most striking feature of this image is the uniform green color, and thus orientation, of the constituent grains. This indicates that the prior-beta grain orientations have a $\langle 101\rangle$ direction aligned with the plate normal direction. This orientation is also evident from the pole figures, which show a strong texture component at the center of the 101 pole figure. The orientation spread exhibited in the pole figure representations corresponds to the color (and orientation) variations present in the EBSD image. The differently colored regions are separated by low-angle boundaries; high-angle grain boundaries are almost completely absent. The uniformity of grain orientations and corresponding dearth of high-angle grain boundaries is characteristic across the weld nugget.

The crystallographic texture of the reconstructed beta microstructure is also shown in Figure 5(b). The symmetry, number of peaks, and uniformity of their intensity reveal that this texture corresponds to slight variations about a single specific crystal orientation with 101 at the center and 111 towards the right. Comparing this orientation to ideal shear textures of bcc alloys ${ }^{[26,33]}$ (see Figure 5(c)) reveals this to correspond to the bcc $D_{1}$ ideal shear texture. (Recall that, for this particular viewing orientation and location in the weld, the shear direction is towards the right and the shear plane normal is upwards, in agreement with the orientation of the calculated shear textures.) This provides further support that the $\beta$ transus temperature is exceeded during welding and that the shear deformation introduced by the rotating tool generates a strong $D_{1}$ shear texture in the high-temperature $\beta$ phase that causes all the component grains to align in approximately the same orientation across the weld. The relatively small orientation variation about the ideal shear orientation generates slightly misoriented grains that are separated almost exclusively by low-angle boundaries. Upon cooling, the weld nugget undergoes an allotropic phase transformation to the low-temperature $\alpha$ phase, refining the original $\beta$ grain structure. The $\alpha$ variants generated from the $\beta$ microstructure are restricted by the parent $\beta$ phase texture (Figure 5(b)). Significant variant selection occurs during the allotropic phase transformation, resulting in a preferential formation of the $P_{1}$-oriented $\alpha$ variants and lesser populations of the other possible orientation variants, as displayed in Figure 5(a). While several mechanisms may influence this variant selection, the high strains and complex thermal history associated with FSW suggest that either prior dislocation activity in the beta phase or residual stresses are most influential. Additional work is needed to further elucidate the variant selection mechanism.

A relatively wide (1 to $2 \mathrm{~mm}$ ) transition region is usually present between the base plate and the weld nugget on each side of the weld (see Figure 6). By comparison, the width of the thermomechanically affected zone in a near-alpha Ti-5111 alloy conventional friction stir weld was only about $500 \mu \mathrm{m} .^{[15]}$ In this transition region, an intermediate structure and orientation is observed between the small, equiaxed red/ orange grains of the base plate and the larger red/blue acicular grains of the weld nugget. These transitional grains are about twice as large as the base plate grains and still retain a convex grain shape. Although they are much more angular than the base plate grains, they do not exhibit the high-aspect-ratio (acicular) characteristics of the weld nugget grains. In addition, the texture of these grains differs from that of both the base plate and weld nugget, exhibiting a significant volume fraction of grain orientations near $2 \overline{11} 0$ (green in color). (Note that the shear direction is vertical at these locations in the weld, corresponding to a $90 \mathrm{deg}$ rotation from the conventional setting of pole figures that display ideal shear texture components.) Pole figures from these 

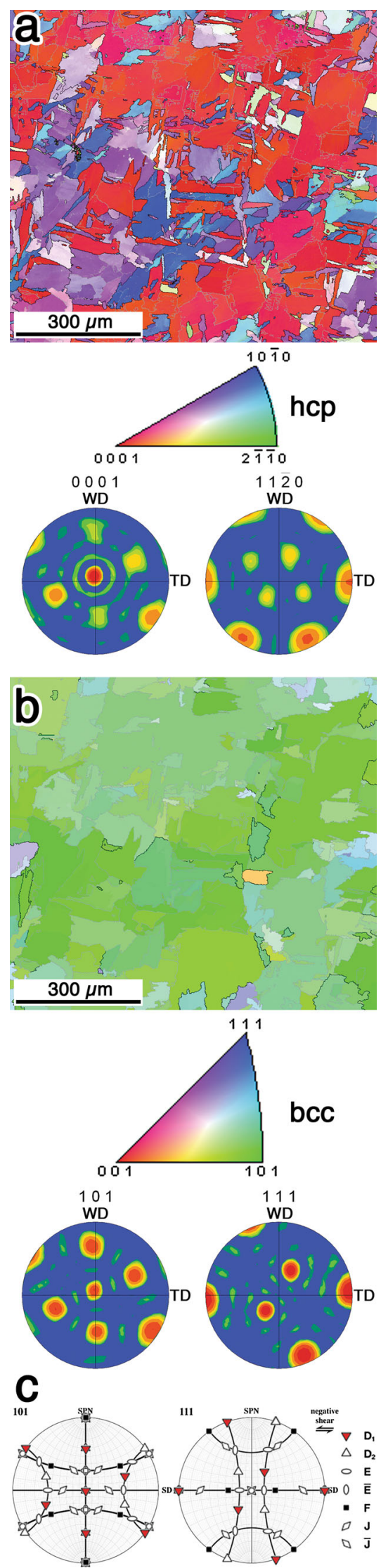

4Fig. 5- (a) The as-acquired plan-view EBSD image from the alpha phase and $(b)$ reconstruction of calculated beta phase orientation from the center of the weld (see Fig. 3), with their associated pole figures. Stereographic triangles indicate crystal orientation along the plate normal direction. High-angle $(>15 \mathrm{deg})$ and low-angle (2 to 15 deg) boundaries in EBSD images are indicated by black and gray lines, respectively. (c) Schematic of bcc ideal shear texture components, after Fonda. ${ }^{[26]}$

regions reveal a significant contribution from the hcp Y ideal shear texture that is strongest on the advancing (left) side. These characteristics indicate that the shear deformation was predominantly introduced while the material was in the low-temperature hcp alpha phase. Thus, these transitional grains are located within the thermomechanically affected zone where they were exposed to sufficient heat to induce grain growth, but did not exceed (at least substantially) the beta transus temperature. This is unique to the TSW process, for which the heated region is not limited by the transmission of deformation from the rotating tool, but is instead strongly influenced by the characteristics of the external heat source.

Reconstructed images of the $\beta$ grain structures at these transitional regions are shown in Figure 7. As mentioned previously, determining an original beta grain orientation that led to the observed base plate $\alpha$ grains is not possible since each base plate grain contains only a single $\alpha$ crystal orientation. This single orientation is not sufficient to determine which beta variant gave rise to that alpha grain so those regions appear black in the figure. The extent of the transition region between the base plate and the weld nugget is much more apparent in this beta reconstructed image, exhibiting a range of orientations (colors) and a gradient of grain sizes that increases towards the weld nugget. The similarity between the observed alpha grain structures and the reconstructed beta structures supports the conclusion that this transitional material was heated sufficiently to allow grain coarsening, but that the temperature did not exceed the allotropic phase transformation temperature.

Inside the weld nugget, the microstructures present on either side of the weld exhibit a uniform grain orientation and scarcity of high-angle boundaries similar to that observed at the weld center, although the transition to that microstructure is more gradual on the retreating side. This indicates that the resultant microstructure and texture are uniform across the weld nugget (other than the orientation variations due to the changing shear orientation).

An EBSD analysis across the weld transverse cross section was also conducted to reveal the grain structure of the transition region as a function of depth in the weld (Figure 8). To preserve a similar orientation across the weld and maintain consistency with the plan-view images, the crystallographic orientations displayed in Figure 8 reflect the crystallographic directions aligned with the plate normal direction (instead of along the viewing direction, which corresponds to the more typical 


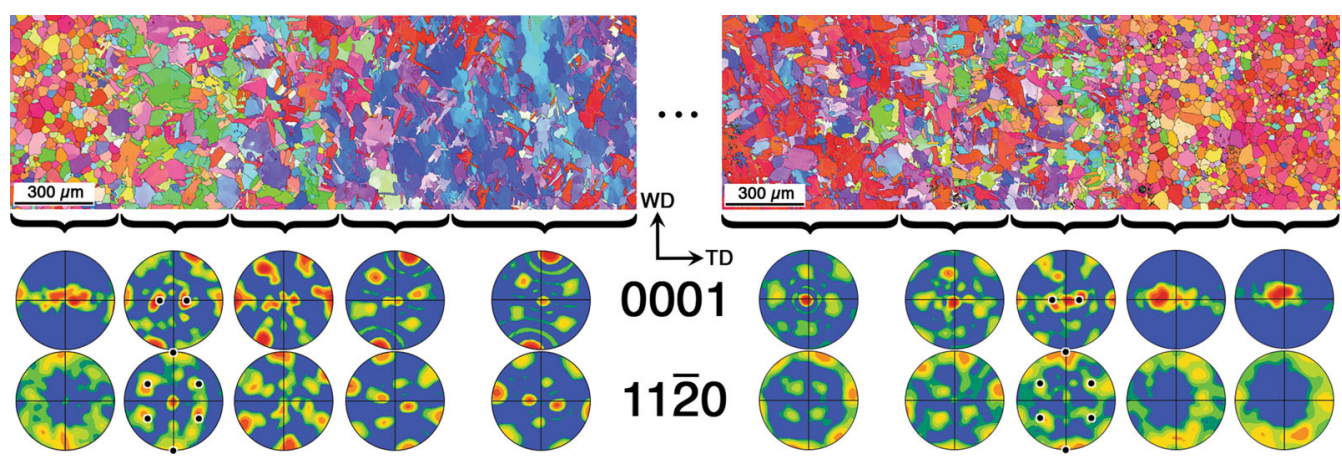

Fig. 6-Plan-view EBSD images of the alpha phase microstructures in the advancing side (left) and retreating side (right) transition regions indicated in Fig. 3 and their associated pole figures with the location of the hop Y ideal shear texture components indicated. High-angle boundaries ( $>15 \mathrm{deg}$ ) are indicated by black lines, and low-angle ( 2 to $15 \mathrm{deg}$ ) boundaries are indicated by gray lines. Colors indicate crystallographic orientation aligned with the plate normal direction according to stereographic triangle shown in Fig. 5(a) (Color figure online).

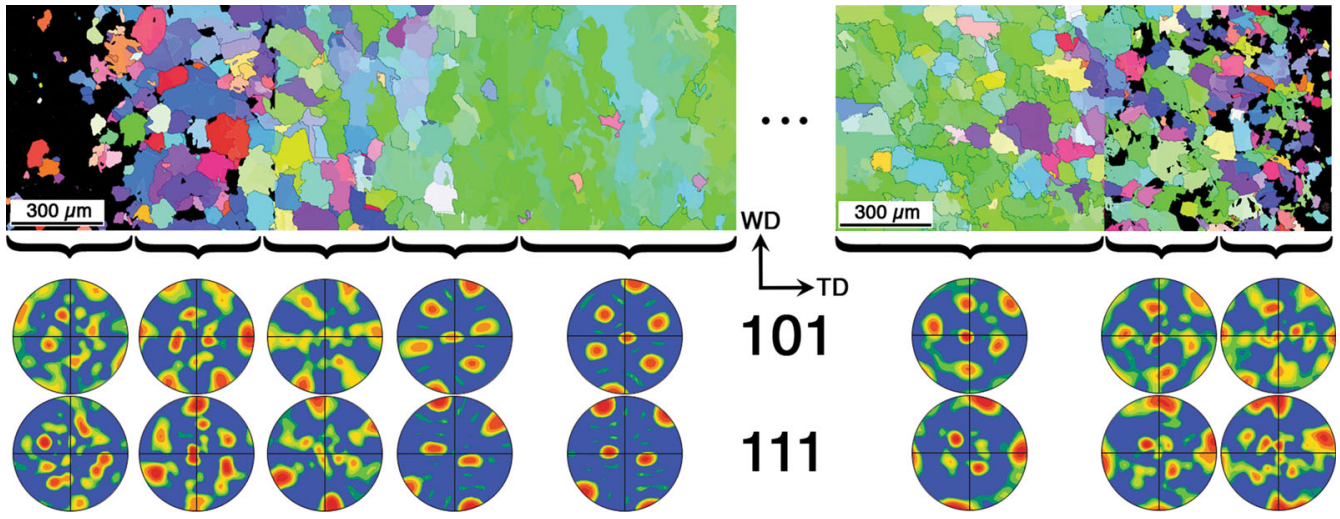

Fig. 7-Plan-view EBSD images of the beta reconstructed grain structures in the advancing side (left) and retreating side (right) transition regions indicated in Fig. 3 and their associated pole figures. High-angle boundaries ( $>15 \mathrm{deg})$ are indicated by black lines, and low-angle ( 2 to 15 $\mathrm{deg}$ ) boundaries are indicated by gray lines. Colors indicate crystallographic orientation aligned with the plate normal direction according to stereographic triangle shown in Fig. 5(b) (Color figure online).

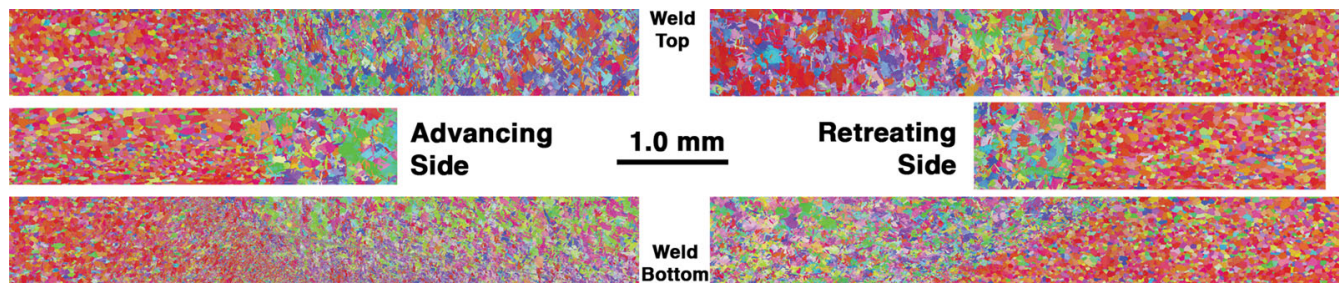

Fig. 8-EBSD images from the transverse cross section showing the advancing side (left) and retreating side (right) transition regions at the top, middle, and base of the weld as indicated in Fig. 3 and their associated pole figures. Colors indicate crystallographic orientation aligned with the plate normal direction according to stereographic triangle shown in Fig. 5(a) (Color figure online).

transverse cross-section surface normal). At the top and center of the weld, both the as-acquired scans of the alpha structure and the beta reconstructions of those structures exhibit vertical weld nugget boundaries and similar microstructures (grain sizes, shapes, and orientations) to those discussed above. However, some differences become evident at the base of the weld. The weld nugget boundary becomes severely inclined at the base of the weld, reflecting the overall shape of the weld shown in Figure 1. The texture of the weld nugget at the base of the weld is similar to that observed higher in the weld although it is rotated more than $40 \mathrm{deg}$ from those textures, in accordance with the inclination of the weld nugget boundary at this location. This causes the orientation (and color) of the weld nugget grains to differ from what is observed higher in the weld. The most prominent characteristic difference is in the grain sizes of both the weld nugget and the adjacent thermomechanically affected zone. Substantial grain refinement is observed at both locations, due to the lower temperatures that are caused by a combination of the decreased heat input from the induction coil and smaller tool cross section and the heat sink effect from the supporting anvil. 


\section{CONCLUSIONS/SUMMARY}

The TSW process, a variant of FSW that uses an induction coil to preheat the region to be welded, is a viable process for joining thicker and high-strength materials. Analysis of the grain structure and texture of both the low-temperature alpha phase of the cooled weld and the high-temperature beta phase that was reconstructed from the alpha phase reveals a strong bcc $D_{1}$ ideal shear texture across the weld nugget. The texture is maintained across the weld nugget, although its orientation rotates as a function of position across the weld similar to the expected variation in shear direction around the tool. The strength of the shear texture causes the prior-beta grains to all have a similar orientation, resulting in a very low concentration of high-angle grain boundaries within the weld nugget. However, cooling through the allotropic phase transformation causes this microstructure to refine into multiple orientation variants of acicular alpha. Strong variant selection was observed, preferably aligning (0001) poles along the plate normal direction, presumably due to effects of the welding residual stresses during the phase transformation. Despite this, there was a sufficient multiplicity of crystallographic variants in the weld nugget that, in conjunction with the observed variation in alpha lath orientations, generate a strength and ductility of the weld that is nearly equal to those of the parent metal. ${ }^{[22]}$ A relatively wide transition region exists between the base plate and the weld nugget which has undergone grain coarsening but does not appear to have exceeded the allotropic phase transformation temperature. While this appears to be a conventional heat-affected zone that was generated by the induction preheating process, the presence of an hcp Y ideal shear texture indicates that welding shear deformation extended into this region, more correctly identifying it as a portion of the thermomechanically affected zone.

At the base of the weld, the weld microstructures reflect the influence of lower temperatures from the reduced induction heating, smaller tool cross section, and the heat sink effect from the underlying anvil. These factors cause a substantial refinement in the grain size at the base of the weld and also limit the width of the weld nugget. A bcc $D_{1}$ ideal shear texture is still generated at the base of the weld, although the orientation of this texture is tilted further from the tool axis, in accordance with the observed weld nugget boundary orientation.

\section{ACKNOWLEDGMENTS}

The authors would like to thank Bryant Walker and Raymond Walker of Keystone Synergistic Enterprises for providing the samples used in this study. We also acknowledge many helpful discussions with Dr. David Rowenhorst. Finally, RWF and KEK would like to thank the Structural Metallics programs office at the Office of Naval Research for their financial support, and ALP would like to acknowledge support from the
Air Force Research Laboratory's Materials and Manufacturing Directorate.

\section{REFERENCES}

1. R.S. Mishra and M.W. Mahoney: Friction Stir Welding and Processing, ASM International, Materials Park, 2007.

2. W.M. Thomas, E.D. Nicholas, J.C. Needham, M.G. Murch, P. Temple-Smith, and C.J. Dawes: G.B. Patent Application No. 9,125,978.8, 1991: U.S. Patent No. 5,460,317, 1995.

3. J.A. Schneider and A.C. Nunes, Jr: Metall. Mater. Trans. B, 2004, vol. 35B, pp. $777-83$.

4. R.S. Mishra and M.W. Mahoney: Friction Stir Welding and Processing, Materials Park, ASM International, 2007, p. 25.

5. W.-B. Lee, C.-Y. Lee, W.-S. Chang, Y.-M. Yeon, and S.-B. Jung: Mater. Lett., 2005, vol. 59, pp. 3315-18.

6. B. Girvin: EWI Report No. 49478GTH, Columbus, OH, October 2006.

7. B. Walker: Keystone Synergistic Enterprises, Inc., ONR/SBIR Contract N00014-06-C-0052 Interim Report 0052-01-08, Port Saint Lucie, FL, January 2008.

8. Y. Zhang, Y.S. Sato, H. Kokawa, S.H.C. Park, and S. Hirano: Mater. Sci. Eng. A, 2008, vol. 488, pp. 25-30.

9. S. Mironov, Y.S. Sato, and H. Kokawa: Acta Mater., 2009, vol. 57 , pp. 4519-28.

10. P.S. Pao, R.W. Fonda, H.N. Jones, C.R. Feng, and D.W. Moon: in Friction Stir Welding and Processing V, R.S. Mishra, M.W. Mahoney, and T.J. Leinert, eds., TMS, Warrendale, 2009, pp. 29-38.

11. K. Reshad Seighalani, M.K. Besharati Givi, A.M. Nasiri, and P. Bahemmat: J. Mater. Eng. Perform., 2010, vol. 19 (7), pp. 955-62.

12. Y. Zhang, Y.S. Sato, H. Kokawa, S.H.C. Park, and S. Hirano: Sci. Technol. Weld. Join., 2010, vol. 15 (6), pp. 500-05.

13. H. Fujii, Y. Sun, H. Kato, and K. Nakata: Mater. Sci. Eng., 2010, vol. 527, pp. 3386-91.

14. R.W. Fonda and K.E. Knipling: Acta Mater., 2010, vol. 58, pp. $6452-63$.

15. K.E. Knipling and R.W. Fonda: Metall. Mater. Trans. A, 2011, vol. 42 A, pp. 2312-22.

16. I. Weiss and S.L. Semiatin: Mater. Sci. Eng. A, 1999, vol. A263, pp. $243-56$

17. X. Long and S.K. Khanna: Sci. Technol. Weld. Join., 2005, vol. 10 (4), pp. 482-87.

18. W.A. Ferrando: Naval Surface Warfare Center Technical Report NSWCCD-61-TR-2008/13, 2008

19. B.N. Bhat, R.W. Carter, R.J. Ding, K.G. Lawless, A.C. Nunes, Jr., C.K. Russell, and S.R. Shah: in Friction Stir Welding and Processing, K.V. Jata, M.W. Mahoney, R.S. Mishra, S.L. Semiatin, and D.P. Field, eds., TMS, Warrendale, PA, 2001, pp. 117-27.

20. B.M. Tweedy, W. Arbegast, and C. Allen: in Friction Stir Welding and Processing III, K.V. Jata, M.W. Mahoney, R.S. Mishra, and T.J. Lienert, eds., TMS, Warrendale, PA, 2005, pp. 97-104.

21. R.J. Ding, J. Schneider, and B. Walker: Proceedings of the Twenty-First (2011) International Offshore and Polar Engineering Conference, International Society of Offshore and Polar Engineers (ISOPE), Cupertino, CA, 2011.

22. B. Walker: Keystone Synergistic Enterprises, Inc., ONR/SBIR Contract N00014-06-C-0052 Final Report Number N0001406-C-0052, Port Saint Lucie, FL, December 2010.

23. G. Kohn, Y. Greenberg, I. Makover, and A. Munitz: Weld. J., 2002, vol. 81 (2), pp. 46-48.

24. S.C. Wang, M. Aindow, and M.J. Starink: Acta Mater., 2003, vol. 51, pp. $2485-2503$.

25. M.M.Z. Ahmed, B.P. Wynne, W.M. Rainforth, and P.L. Threadgill: Scripta Mater., 2008, vol. 59, pp. 507-10.

26. R.W. Fonda and K.E. Knipling: Sci. Technol. Weld. Join., 2011, vol. 16, p. 288

27. R.W. Fonda, K.E. Knipling, and D.J. Rowenhorst: JOM, 2014, vol. 66 (1), pp. 149-55.

28. A.L. Pilchak and J.C. Williams: Metall. Mater. Trans. A, 2011, vol. $42 \mathrm{~A}$, pp. $773-94$.

29. M. Humbert, H. Moustahfid, F. Wagner, and M.J. Philippe: Mater. Sci. Forum, 1994, vol. 157, pp. 1225-30. 
30. M. Humbert, F. Wagner, H. Moustahfid, and C. Esling: J. Appl. Cryst., 1995, vol. 28, pp. 571-76.

31. M.G. Glavicic, P.A. Kobryn, T.R. Bieler, and S.L. Semiatin: Mater. Sci. Eng. A, 2003, vol. 346, pp. 50-59.
32. M.G. Glavicic, P.A. Kobryn, T.R. Bieler, and S.L. Semiatin: Mater. Sci. Eng. A, 2003, vol. 351, pp. 258-64.

33. S. Li, I.J. Beyerlein, and M.A.M. Bourke: Mater. Sci. Eng. A, 2005, vol. A394 (1-2), pp. 66-77. 